Neuropsychologia, Vol. 20, No. 2, pp. 181 - 186, 1982.

\title{
TOPOGRAPHIC INSTABILITY OF SPATIAL VISION AS A CAUSE OF DYSLECTIC DISORDER: A CASE STUDY
}

\author{
GÖTE NYMAN and PENTTI LAURINEN \\ University of Helsinki, Department of General Psychology, Ritarikatu 5,00170 Helsinki 17, Finland
}

and

LEA HYVÄRINEN

University of Oulu, Department of Ophthalmology, Oulu, Finland

(Received 3 September 1981)

\begin{abstract}
A case of severe disorder of spatial perception with concomitant dyslexia is described. The patient, a 15-yr-old girl, has a systematic tendency to misperceive the spatial order of symbols or objects lying on the same horizontal level and within a few degrees of visual angle. The syndrome includes a spatial extinction phenomenon in which an object in her left visual field disturbs the perception of another object in the corresponding symmetry point of her right visual field. The order reversal symptom was abolished if the letters presented for her were shown for less than $15 \mathrm{msec}$. The disorder is probably due to a pathological interhemispheric interference in the processing of visual topographic information.
\end{abstract}

SOME dyslectic children suffer from a reading disorder which causes them to confuse the order of letters in written text. The mechanism behind the symptom is not known. Sometimes brain damaged adults have rather similar symptoms and in most severe cases their reading difficulties occur together with a more general distortion of spatial perception and behaviour [1]. In such cases the cause is typically a parietal cortical lesion, especially in the gyrus angularis region. Often the brain damaged patients and dyslectic children mix the letter order of text even though there is not necessarily confusion about the letters themselves.

In analysing the cause of dyslectic symptoms, it is necessary to know the dynamics of the reading or writing disorders in order to reveal the actual mechanism which is causing the pathological behaviour. This is not a simple task in clinical practice because the symptoms are not always systematic which makes it difficult to quantify them. For example, because the letter reversal phenomenon does not usually occur for all the words the patient reads, it is not always possible to measure the spatial and temporal parameters effecting it.

We describe here an exceptional case of a 15-yr-old girl N.N. who was investigated in our laboratory because of dyslectic symptoms involving a strong and systematic tendency to misperceive spatial order of adjoining symbols or objects lying at the same horizontal level. Because of the nature of the symptoms, a special psychophysical method could be applied in studying her performance in simple letter perception tasks. The method was developed to estimate the spatial and temporal determinants of the symptom and it was found out that by means of a suitable presentation of stimuli we could abolish the reversal symptom. 
Subject

METHOD

Our subject was earlier examined by a number of ophthalmologists who considered her visual functions normal, except a slightly insufficient accommodation and convergence. Central visual acuity was measured with visual acuity charts.

At the time of the experiments described here she had binocular corrected visual acuity of 0.5 in line test. If the symbols were pointed at, the binocular acuity was 1.5, RE 1.0, LE 1.25. She still had normal binocularity, but insufficient convergence and accommodation $(25 \mathrm{~cm})$. Near vision acuity with single symbols was 0.25 and with grouped symbols 0.1 at $40 \mathrm{~cm}$. She reported consistently the first and second symbol in each group in reverse order. At first the two symbols seemed to overlap for a while after which they stayed steady but in reverse order. She had herself learned to prevent this by holding a pen below the text or by using a Visolette magnifying lens. The peculiar apparent movement of objects was not confined to letters only, also three-dimensional objects within $3-5^{\circ}$ central field were seen in reverse order. However, she did not have difficulties in left right discrimination nor other symptoms typical for the Gerstmann syndrome.

Her visual fields were studied with Goldmann perimetry and were of normal size. The responses in field testing were consistent in all other meridians except temporal to the midline in both upper fields, where a $10^{\circ}$ step was present in the midline.

Her contrast sensitivity function (CSF) was normal with no unusual characteristics for a case of slightly impaired visual acuity. Nothing abnormal was found in her ERG which was studied by using several light intensities. Also the visual evoked responses (VEP) which were measured by using contrast reversing technique with checkerboard stimuli had normal latency and amplitude values. The VEP responses were measured monocularly and binocularly with stimuli having the square size of 6,16 or $48^{\prime}$ of arc and the total stimulus size of $15 \times 15^{\circ}$.

Except for the problems described above, her motor and perceptual functions did not show any abnormalities. She is fluent in co-operation and has no difficulties in speech or other normal behaviour. Her family background is very supportive and educated. In other words, the main symptoms found were the peculiar reversal phenomenon with concomitant dyslexia and rather poor effect of correction by lenses.

\section{Apparatus and procedure}

The visual stimuli were produced by a microprocessor controlled stimulation and threshold measuring system designed by G. Nyman. It allowed the presentation of spots of light at any location of an oscilloscope (Tektronix 5104A) screen. Two characters, " $A$ " and " $V$ " were shown, both lying on the same horizontal level and simultaneously present. The subject's task was to report whether she saw the configuration " $A-V$ " or " $V-A$ ". If she gave the correct response the distance between the characters was decreased by $0.25^{\circ}$ and if the response was incorrect it was increased. A sound signal before the stimulus onset signalled that she should fixate at a fixation cross which was located in the middle between the characters or in some experiments laterally from them. Each character was formed of 10 spots of light and they were presented against a background having the luminance of $18 \mathrm{~cd} / \mathrm{m}^{2}$. The luminance of the spots was not measured, but they were above the threshold and visible at all the presentation times used.

A sequential estimation method [2] was used to measure the threshold values. The procedure which involved the presentation of stimulus blocks was designed to estimate the point one psychometric function which corresponds to the probability of 0.707 of correct response.

Mainly monocular vision was studied, with right eye covered but some controls were also run binocularly. No artificial pupil was used. Viewing distance was $114 \mathrm{~cm}$, the characters were of the size $0.5 \times 0.75^{\circ}$ and the frame frequency of the spots was $400 \mathrm{~Hz}$.

\section{RESULTS}

To demonstrate the symptom of letter order reversal, some of the drawings of N.N. are presented. She made them to describe what she actually saw in different stimulus situations. As she could also verbally describe the appearance of the stimuli and because she had learned to write visually presented or dictated words correctly, her descriptions can be taken as actually representing how the letters appeared to her. 


\section{Experiment I}

We asked N.N. to draw the characters exactly as she saw them when different presentation durations and letter separations were used. Otherwise the viewing was as described above.

\begin{tabular}{|c|c|c|c|c|c|}
\hline Space (deg) & .5 & 1.0 & 1.5 & 2.0 & 2.5 \\
\hline Stimulus & A V & A V & A V & A V & $A V$ \\
\hline Appearance & A & VA & VA & A & $A V$ \\
\hline Time (msec) & 7.5 & 15 & 25 & 50 & 100 \\
\hline Stimulus & AV & A V & A V & A V & AV \\
\hline Appearance & AV & $x$ & $D_{1}$ & $V A$ & $V A$ \\
\hline
\end{tabular}

Fig. 1. (A) The subject's drawings of the letters as she saw them when they were presented for 500 msec duration. Different letter separations are indicated by the space in degrees. between the letters. (B) Her drawings when the letters were presented for a variable duration but always at constant separation, which was $0.5^{\circ}$.

Firstly, a 500 msec stimulus, either " $A-V$ " or " $V-A$ " in a random order was given and she could not know in advance which letter pair would be shown. The lateral separation between the letters was also varied and for each value she drew what she saw. The drawings from five different separations are seen in Fig. 1 (A). The letters have been copied by hand from the originals.

Clearly, decreasing the separation made the perceived separation decrease relatively more and after a point of overlap, reversal took place. As seen later in experiment II the threshold separation for reversal measured with a $500 \mathrm{msec}$ stimulus was about $2^{\circ}$ or less. Below this threshold value, smaller separations consistently induced the reversal.

Secondly, we studied the effect of presentation duration upon the reversal effect when the letters shown were so near each other that reversal always occurred at long durations. We chose the value of $0.5^{\circ}$ for this purpose. In Fig. 1 (B) it is seen that if the duration was about $15 \mathrm{msec}$, the letters she saw were overlapping as would be expected on the basis of the results seen in Fig. 1 (A). Now increasing the duration also increased the probability of reversal. These results could be obtained consistently as was typical for her performance.

\section{Experiment II}

In this experiment we studied the reversal symptom more quantitatively. The letter pair " $A-V$ " or " $V-A$ " was again presented in a random fashion. The separation needed for correct identification of the stimuli was determined by using the psychophysical threshold measuring procedure. Both foveal and eccentric vision were studied by using different points of fixation. Presentation time of each pair was varied between 5 and $1000 \mathrm{msec}$ and one threshold run was performed for each time value. The results are seen in Fig. 2.

The reversal occurred when the duration of presentation was more than about 10-12 msec, but if the duration was short enough, she made no errors at all. When the duration was increased the reversal started to occur but not as a monotonically increasing function of time but rather as a U-function. At the time of about $50 \mathrm{msec}$ there was a minimum. threshold separation for reversal, i.e. about $0.5^{\circ}$. 


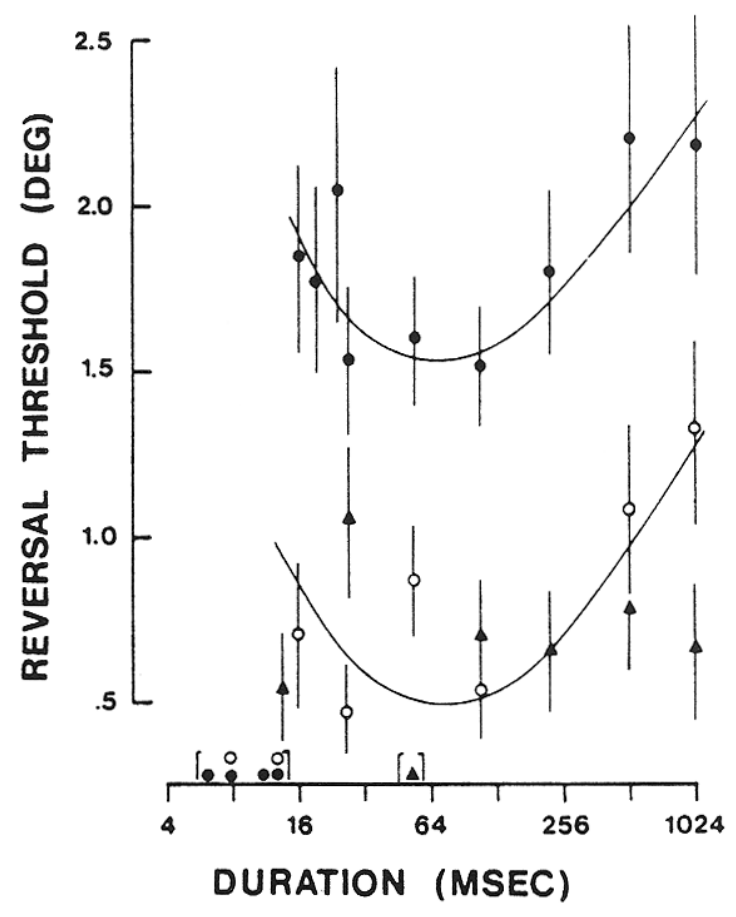

FIG. 2. Effect of stimulus duration on the letter reversal thresholds in monocular vision (left eye). Threshold for reversals is expressed in terms of angular distance between the two letters " $A$ " and " $V$ " which was necessary for the subject to identify the letter order correctly. Measurements for different eccentricities are depicted by different symbols. •: fixation point was located in the middle between the letters. $\Delta: 3.5^{\circ}$ temporally, and $0: 7^{\circ}$ temporally from the midpoint between the letters. Note that no reversal occurred with presentation times shorter than about $15 \mathrm{msec}$. This is indicated by the symbols lying on the horizontal axis. The curves through the lines have been drawn by eye. The bars represent \pm 1 S.D.

Also the eccentricity of presentation had an effect upon the thresholds; when the eccentricity was increased, the letters could be more adjoining than in the central foveal vision for correct identification of the order. Thus the effect is not simply related to visual acuity because acuity falls considerably at this eccentricity [3].

\section{DISCUSSION}

Having found the symptoms described above we ruled out some alternative hypothesis about their cause. Firstly, we concluded that the defect was probably not induced by pathological eye movements because the duration of presentation needed for the elimination of the reversal effect was extremely short, i.e. about $10-12 \mathrm{msec}$. This is much less than would be expected if we assume that the eye movement effects are eliminated by the short presentation which allows "steady" stimulation of the retina. Also clinically N.N. had normal eye movements and no signs of excessive saccades or drifts were noted. If the symptoms were produced by some kind of "inertia" in the processing of retinal information received from the moving eyes, then it would be expected that she should also have rather large eye movements to cover the measured threshold separation which was between 0.5 and $2.0^{\circ}$.

Secondly, it could be suggested that the defect is caused by some cortically operating mechanism analysing the distances between the stimulated points on the visual cortex itself. If so, then the reversal phenomenon would have higher separation threshold in the periphery than in the central fovea because for a given stimulated cortical area a larger retinal area is needed in the periphery than in the central fovea. This is due to the effects of the cortical magnification factor [3]. This is contradictory to our finding that for N.N. the letters could be nearer to each other in the periphery than in the central fovea for correct identification of the letter order. 
Because of the effect of eccentricity on her errors we also considered the possibility of an interhemispheric origin for the disorder. To study this we performed a simple clinical extinction test which is often used in examining somatosensory functions, but now using visual stimuli. We asked her to fixate her gaze at a fixation cross while at the same time a letter stimulus was presented to the right of the fixation point. She could easily identify different-sized letters presented eccentrically. If at the time of letter presentation, also a black spot of equal size was waved back and forth in the corresponding symmetry point in the left visual field, she reported that the letter disappeared completely from her vision. This could be demonstrated either binocularly or with the left eye monocularly. The masking or extinction effect was effective only if the masking spot was located in the left visual field. This does not, of course, disturb normal vision.

Evidently, the extinction and reversal phenomena are interrelated and as a complex syndrome they create a perceptually difficult situation for the patient, because they introduce interaction effects between the letters in the text which she is reading. This explains also why she complained about fuzziness and instability of spatial vision in general. It is possible that the instability is due to interhemispheric interference and that at short presentation times the contralaterally originating disturbance does not have enough time for distorting the ipsilateral signals. This hypothesis is also supported by the finding that shifting the stimuli eccentrically which causes them to stimulate predominantly one hemisphere, also weakens the disturbance. How and why this kind of syndrome occurs remains an open question for us in the lack of more detailed neurological information about the subject. However, her case demonstrates several important features about spatial vision: firstly, the existence of symmetric, contralateral interaction, especially extinction, and secondly, the phenomenon of spatial instability in which objects perceptually change place. Together these disturbances weaken the perceptual constancy needed in the development of pattern vision. For her objects seem to change place, interact and disturb each other causing shifts and masking effects which make her reading process visually noisy, unstable, and difficult to master.

\section{REFERENCES}

1. CRITCHLEY, M. The Parietal Lobes. Edward Arnold, London, 1953.

2. WETHERHILL, G. B. and LEVITT, H. Sequential estimation of points on a psychometric function. Br. J. Stat. Psychol. 18, 1-10, 1965.

3. COWEY, A. and ROLLS, E. T. Human cortical magnification factor and its relation to visual acuity. Expl. Brain Res. 21, 447-454, 1974.

4. HEILMAN, K. M. and VALENSTEINE, E. Auditory neglect in man. Arch. Neurol. 26, 32-35, 1972.

\section{Résumé:}

On présente une observation de trouble grave de la perception spatiale accompagné de dyslexie. La malade âgée de 15 ans montrait une tendance systématique à percevoir de façon erronée l'ordonnancement spatial des symboles ou des objets placés horizontalement et sous quelques degrés d'angle visuel. Le syndrome cornprenait aussi un phénomène d'extinction spatiale: un objet dans son champ visuel gauche perturbe la perception des autres objets dans un point symétrique correspondent de son champ droit. Le symptôme de renversement de l'ordre était aboli si les lettres lui étaient montré durant moins de $15 \mathrm{msec}$. Le trouble est probablement dû à une interférece interhémisphérique pathologique dans le traitement de l'information topographique visuelle.

\section{Zusammenfassung:}

Ein Fall von schwerer Störung der räumlichen Wahrnehmung mit begleitender Dyslexic wird beschrieben. Ein 15jähriges Mädchen hat eine systematische Tendenz, die räumliche Anordnung von Symbolen und Objekten falsch wahrzunehmen, die auf derselben Horizontale und innerhalb einiger weniger Winkelgrade lateral liegen. Das Syndrorn schliesst ein räumliches Auslöschphänomen ein, in dem ein Objekt im linken Gesichtsfeld die Wahrnehmung eines anderen Objektes im dementsprechenden symmetrischen Punkt des rechten Gesichtsfeldes beeinträchtigt. Das Symptom der Umkehrung der Anordnung wurde ausgelöscht, wenn die Buchstaben weniger als 15 Millisekunden dargeboten wurde. Die Störung beruht vermutlich auf einer pathologischen interhemisphärischen Interferenz in der Verarbeitung visueller tomographischer Information. 